\title{
Public Exposure to U.S. Commercial Nuclear Power Plants Induced Disasters
}

\author{
Dean Kyne ${ }^{1}$
}

Published online: 21 September 2015

(c) The Author(s) 2015. This article is published with open access at Springerlink.com

\begin{abstract}
This study explores the potential risks associated with the 65 U.S.-based commercial nuclear power plants and the distribution of those risks among the populations of both their respective host communities and of the communities located in outlying areas. First, it starts by examining the racial/ethnic composition of the host community populations, as well as the disparities in socioeconomic status that exist, if any, between the host communities and communities located in outlying areas. Second, it utilizes two independent-sample $T$ tests to identify any differences in the sociodemographic compositions of the two areas. Third, it explores regional demographic trends by looking at the percent change in demographic variables in the host communities and communities located in outlying areas in 1990-2000 and 2000-2010. Findings reveal that during the past two decades more people were exposed to the risks as population living in the host communities increased.
\end{abstract}

Keywords Exposure to nuclear power disasters - Host communities · Nuclear disasters · U.S. commercial nuclear power plants

\section{Introduction}

The most recent catastrophic nuclear event, which occurred at Japan's Fukushima Daiichi nuclear power plants (NPP) in March 2011, served to remind us of the unpredictable

Dean Kyne

dean.kyne@utrgv.edu

1 Department of Sociology and Anthropology, The University of Texas Rio Grande Valley, Edinburg, TX 78539, USA and extreme risks associated with nuclear power. Other notable NPP accidents include Three Mile Island in the United States in 1979 and Chernobyl in Soviet Ukraine in 1986. The inescapable risk associated with a NPP is substantially amplified when that risk is coupled with any geological or other natural hazards, such as an earthquake, tsunami, flood, or other catastrophic event. On 11 March 2011, a massive earthquake registering a 9.0 magnitude triggered a tsunami that washed up on the coast of Miyagi Prefecture, Japan, where the Fukushima NPP is sited. The earthquake caused a blackout, which brought down the cooling system for the reactors' nuclear fuel rods. The collapse of cooling resulted in the release of radioactive materials into the environment (Baba 2013). The Fukushima NPP was not designed to withstand such a tsunami, despite having been sited near the coast in a tectonically active zone (Acton and Hibbs 2012). Designed to accommodate a tsunami-driven surge estimated to be at most $3.1 \mathrm{~m}$ above sea level, the seawater intake was built at $4 \mathrm{~m}$ above sea level. The building was built $10 \mathrm{~m}$ tall, on a cliff that rises $25 \mathrm{~m}$ above the shoreline. During the event, the seawater pumps were inundated when a $14 \mathrm{~m}$ high wave washed over the coastline. According to Kan (2013), cost savings was the underlying motive behind the decision of Tokyo Electric Power Company (TEPC) to go forward with such a low projected height for a tsunami-driven surge in its design and construction of the Fukushima NPP. In the long-run, the pay-off from the cost savings came with a price tag far beyond anything one could possibly have imagined.

The immediate threat from any NPP-related disaster comes in the form of ionizing radiation emitted from the core, where the nuclear fuel rods are housed. As part of their normal, day-to-day operations, NPPs emit low levels of ionizing radiation that may pose health risks to those 
living in proximity and subject to prolonged exposure (Blevins and Andersen 2011). In general, the ionizing radiation emitted from NPPs has been linked to various forms of cancer, permanent damage to human vital organs, and death (Astakhova et al. 1998; Cardis et al. 2005; Canu et al. 2008; Anzai et al. 2012). The Fukushima NPP began to release significant excess radiation into the atmosphere the day after the accident (Thakur et al. 2013; Baba 2013).

In the event of a nuclear disaster, ionizing radiation can quickly travel over great distances as the wind carries a radioactive-effluent plume over outlying areas (Cyranoski and Brumfiel 2011). In the aftermath of the event at Fukushima, such radioactive effluents were released in two forms-gaseous and liquid. These effluents included isotopes of noble gases such as xenon $\left({ }^{133} \mathrm{Xe}\right)$, krypton $\left({ }^{85} \mathrm{Kr}\right)$, iodine $\left({ }^{131} \mathrm{I},{ }^{132} \mathrm{I}\right)$, cesium $\left({ }^{134} \mathrm{Cs},{ }^{136} \mathrm{Cs},{ }^{137} \mathrm{Cs}\right)$, and tellurium $\left({ }^{132} \mathrm{Te}\right)$. Due to the high levels of radiation released, the Fukushima accident ranked as a level-7 event according to the International Nuclear Event Scale (INES), where 1 is abnormal and 7 represents a major accident (Thakur et al. 2013). In addition, a large but unknown amount of highly contaminated water was discharged from the three reactors and eventually made its way into the ocean and groundwater (Baba 2013). The amount of water discharged into the ocean was and remains unknown, and TEPC has since informed the public that water that had leaked from one of the more than 1000 storage tanks at the site was found to have radiation levels sufficient to kill a person within $4 \mathrm{~h}$ of exposure (Lazare 2013). An estimated 80,703 gallons of contaminated groundwater continues to flow into the ocean daily (Yamaguchi 2013).

United States commercial NPPs are vulnerable to natural hazard events. When impacted by such a hazard, it is likely that many would prove unable to withstand the event (Cappiello and Donn 2011). Given the number of "near-miss" events recorded over the past 3 years, there would seem to be ample potential for an accident to occur that, with better preparation and strengthened safeguards in place, could have been avoided. The severity of any such accident and its negative impacts on the lives of the people living in the nearby communities would be difficult to overestimate. Evaluation tasks are immense and complex, and cleaning up radioactive contamination requires international experts, immense financial resources, and decades, if not centuries, as the Japanese case is illustrating all too clearly.

The communities that host NPPs inevitably bear the burden of the persistent risks associated with them. In instances in which the host communities were not allowed to participate in the decision-making process that resulted in a NPP being sited in their area, the communities have had to involuntarily bear the risk of negative environmental impacts deriving from the plant, thus raising a number of environmental justice issues.
In the early years of civilian nuclear power, between 1957 and 1975, the U.S. Atomic Energy Commission (AEC) oversaw the NPP siting process. The AEC was founded under the Atoms for Peace program, which was later transformed into the Price-Anderson Act of 1957 (Hochfelder 1999). Under the AEC's guidelines, appropriate site selection was based on Part 100 of Title 10 of the Code of Federal Regulations (CFR), which included three key criteria-exclusion area, low-population zone, and population center distance (Greenberg and Krueckeberg 1974). The AEC's decision making in the siting process saw it exposed to criticism for its having to play dual roles, as both promoter and regulator of nuclear energy (Golay et al. 1977), and for the vagueness of these three key terms (Greenberg and Krueckeberg 1974). Of course, the idea of environmental justice did not exist during the era of AEC administration, so one cannot expect their guidelines to have considered issues of social equity. During its administration, the AEC issued operating licenses for 126 reactors, of which 103 remained in operation, 22 had been shut down, and one was temporarily closed as of August 2012 (U.S. NRC 2012c).

In 1970, the New Environmental Policy Act (NEPA) went into effect and the Environmental Protection Agency (EPA) was established. Part of the EPA's mission was to incorporate environmental justice policy into all federally sponsored projects. In 1975, after take into consideration criticisms of the AEC, the U.S. Nuclear Regulatory Commission (NRC) was founded by the Energy Reorganization Act of 1974 (U.S. NRC 2011b). The NRC was given sole responsibility for the licensing of all nuclear power reactors in the country through a two-step licensing process, which included both a construction and an operating license application (U.S. NRC 2012c). By law, public participation in the licensing process was encouraged through adjudicatory (or courtroom-style) hearings that disclosed the proposed plant's conformity with existing environmental law and any quality of design and construction issues (Mariottee 2006). After 1992, the licensing process was reorganized into a single step. The new, simplified, onestep process has been the subject of some criticism, however, as it placed greater constraints on public participation and bestowed more advantages upon nuclear operators. Public participation was seen to be discouraged by the requirement of legitimate contentions for each public hearing by the Atomic Safety and Licensing Board (ASLB), a three-judge panel of NRC employees made up of two technical experts and one attorney. The time frame during which the public was able to file such contentions was limited to a 60-day window, and the high costs of attorney's fees and the fees needing to be paid to expert witnesses also acted to limit the public's ability to intervene in the licensing process (Mariottee 2006). These procedural limitations might have contributed to decisions made around environmental justice issues that have since 
negatively impacted the health and wellbeing of people living near the power plants.

Environmental equity studies emerged out of the then-nascent environmental justice movement in the U.S. South in the early 1980s. The emergence of anti-NPP movements, however, preceded the environmental justice movement by more than 20 years, linked to preexisting antinuclear-weapons movements of the 1950s (Gottlieb 2005). Beginning in the 1960s, broad antinuclear technology movements began to contest the siting of NPPs at various locations in the United States over concerns of ionizing radiation and the plants' potential for nuclear accidents (Gottlieb 2005). Contested sites included: Calvert Cliffs Nuclear Power Plant, Maryland; Seabrook Station Nuclear Power Plant, New Hampshire; Diablo Canyon Power Plant, California; Shoreham Nuclear Power Plant, North Carolina; and Three Mile Island Nuclear Generating Station, Pennsylvania (Giugni 2004). With the cessation of construction of new NPPs in the United States as of the 1980s, the anti-NPP movement substantially slowed but nuclear power remained a potent local concern, especially in those communities that already hosted nuclear facilities (Gottlieb 2005).

While justice and equity were not part of the discourses of the previous antinuclear power campaigns, they do figure prominently in environmental justice studies. According to Bullard's definition (1996), environmental justice refers to the equal protection from environmental harms of all peoples, regardless of race, sex, income, and age. This definition emphasizes equity as essential to environmental justice. According to Margai (2010), environmental equity has a broader context and engages with the geographical and spatial distribution of environmental risks. For Bullard and colleagues, environmental equity can be distilled into three categories-namely, procedural, geographic, and social equity (Bullard et al. 2007). Procedural equity concerns fairness in environmental decision-making processes, which is often examined by looking into how and whether rules, regulations, and systematic evaluation criteria are applied in a uniform and nondiscriminatory way. Geographic equity investigates whether environmental risks are equally distributed according to the spatial location of communities and their proximity to potentially hazardous and/or toxic facilities. Social equity evaluates how sociological factors - such as race, ethnicity, class, culture, lifestyle, and political power-influence environmental decision making. With its focus on proximitybased assessment, the present study focuses on two types of equity-namely, geographic and social-in attempting to answer the research questions presented below.

With a primary goal of addressing environmental justice issues, President Clinton in 1994 signed Executive Order 12,898 , which required each federal agency to have a plan "that identifies and addresses disproportionately high and adverse human health or environmental effects of its programs, policies, and activities," and to "make environmental justice a part of all they do" (Bowen et al. 1995, p. 641). The 65 NPPs currently operating in the United States, however, all were built between 1964 and 1978 (U.S. NRC 2011b), well before President Clinton's Executive Order was put into effect. That Executive Order now provides grounds for environmental justice assessments based on the current guidelines in place for the NPP siting process as defined by the NRC. The siting decisions of the U.S.-based NPPs currently in operation therefore were made in a period during which the inequitable impacts of industrial hazards simply were not considered in the procedures for the selecting of appropriate sites. Given the by now well-documented evidence that, in many cities, hazardous industries are disproportionately located in areas with predominantly poor and minority populations, the question that naturally follows is: Do NPPs exhibit similar patterns of inequitable proximity to low-income and racial minority populations?

The primary goal of this study is to investigate the potential environmental risks borne by the communities living in proximity to the 104 nuclear reactors at 65 NPPs currently operating in the United States. In particular, this study examines whether minorities and the poor are overrepresented in host communities. Consistent with the emergency evacuation guidelines set forth by the NRC (U.S. NRC 2011a), this study considers two exposure zones that mirror the two emergency planning zones (EPZs) the NRC calls for to surround any NPP: the plume-exposure pathway EPZ, which is the area within a 10-mile radius of a NPP; and, the ingestion pathway EPZ, which is the area within a 50-mile radius. There is no publicly available historical data on different radiation dosage levels as sorted by distance from NPPs that could be used in order to estimate the extent of risk by distance. Therefore, the present study uses a proximity-based assessment of NPPs and measures equity in terms of the distribution of outcomes. Proximity-based assessment focuses on exposure to risk arising from the presence of a hazardous or toxic facility and makes no attempt to analyze the extent of the risk (Cutter et al. 1996; Bolin et al. 2002) - that is, the assumption is made that, all else being equal, living closer to a NPP is riskier than residing in a more distant location.

In order to achieve the primary goal to this study, the author sought an answer to the following question: Are the disparities in the sociodemographic characteristics of the populations of communities within a 50-mile radius of a NPP greater than the same disparities of populations living in communities that are outside of a 50-mile radius from a NPP?

\section{Study Area and Data}

The study area and types of data used in the study are discussed as follows. 


\subsection{Study Area}

This study includes data from 104 U.S.-based commercial nuclear power reactors, distributed across 65 NPPs, as of January 2011 (Fig. 1) (U.S. NRC 2012a). Many are clustered along the U.S. eastern seaboard; in fact, there are only eight reactors at four NPPs in the American West. One reason for this concentration might be that the U.S. East Coast has a greater demand for electricity consumption due to its denser population; another might be that the West coast is far more tectonically active, with some areas up to 100 times more likely to experience an earthquake than any place on the East



\begin{tabular}{|c|c|c|c|}
\hline Index & Nuclear Power Plant, State & Index & Nuclear Power Plant, State \\
\hline 1 & Browns Ferry, Alabama & 34 & Seabrook, New Hampshire \\
\hline 2 & Farley, Alabama & 35 & Hope Creek, New Jersey \\
\hline 3 & Palo Verde, Arizona & 36 & Oyster Creek, New Jersey \\
\hline 4 & Arkansas Nuclear, Arkansas & 37 & Salem, New Jersey \\
\hline 5 & Diablo Canyon, California & 38 & Indian Point, New York \\
\hline 6 & San Onofre, California & 39 & FitzPatrick, New York \\
\hline 7 & Millstone, Connecticut & 40 & Nine Mile Point, New York \\
\hline 8 & Crystal River, Florida & 41 & Ginna, New York \\
\hline 9 & Saint Lucie, Florida & 42 & Brunswick, North Carolina \\
\hline 10 & Turkey Point, Florida & 43 & McGuire, North Carolina \\
\hline 11 & Hatch, Georgia & 44 & Shearon Harris, North Carolina \\
\hline 12 & Vogtle, Georgia & 45 & Davis-Besse, Ohio \\
\hline 13 & Braidwood, Illinois & 46 & Perry, Ohio \\
\hline 14 & Byron, Illinois & 47 & Beaver Valley, Pennsylvania \\
\hline 15 & Clinton, Illinois & 48 & Limerick, Pennsylvania \\
\hline 16 & Dresden, Illinois & 49 & Peach Bottom, Pennsylvania \\
\hline 17 & La Salle, Illinois & 50 & Susquehanna, Pennsylvania \\
\hline 18 & Quad Cities, Illinois & 51 & Three Mile Island, Pennsylvania \\
\hline 19 & Duane Arnold, Iowa & 52 & Catawba, South Carolina \\
\hline 20 & Wolf Creek, Kansas & 53 & Robinson, South Carolina \\
\hline 21 & River Bend, Louisiana & 54 & Oconee, South Carolina \\
\hline 22 & Waterford, Louisiana & 55 & Summer, South Carolina \\
\hline 23 & Calvert Cliffs, Maryland & 56 & Sequoyah, Tennessee \\
\hline 24 & Pilgrim, Massachusetts & 57 & Watts Bar, Tennessee \\
\hline 25 & D.C. Cook, Michigan & 58 & Comanche Peak, Texas \\
\hline 26 & Fermi, Michigan & 59 & South Texas, Texas \\
\hline 27 & Palisades, Michigan & 60 & Vermont Yankee, Vermont \\
\hline 28 & Monticello, Minnesota & 61 & North Anna, Virginia \\
\hline 29 & Prairie Island, Minnesota & 62 & Surry, Virginia \\
\hline 30 & Grand Gulf, Mississippi & 63 & Columbia, Washington \\
\hline 31 & Callaway, Missouri & 64 & Kewaunee, Wisconsin \\
\hline 32 & Cooper, Nebraska & 65 & Point Beach, Wisconsin \\
\hline 33 & Fort Calhoun, Nebraska & & \\
\hline
\end{tabular}

Fig. 1 U.S. commercial NPPs in operation as of August 2012; decommissioned or otherwise inactive NPPs have been omitted. Source U.S. NRC (2012a) 
coast. The NPPs sited on the East coast do not include in their designs technologies or design features meant to mitigate against strong earthquakes, and therefore cost less to build than would an otherwise similar NPP on the West Coast (Koch 2011).

This study includes two discrete study areas. One is those areas within a 50-mile radius of any one of the 65 U.S.-based NPPs (Fig. 1); the other is those areas outside of a 50-mile radius and yet that are located in the state(s) that fall within said 50-mile radius. This study excludes from its analysis 20 reactors that have been permanently deactivated. Among them, seven reactors are located at NPPs that otherwise remain active. These 20 reactors do not pose the same level of risk as do reactors currently in operation. Functioning reactors pose increased risks as a result of their day-to-day operation, the possibility of a core meltdown-type accident, and their potential release of gaseous and liquid radioactive effluents. Reactors may also represent a potential radiation risk as a result of any spent fuel that is stored on site. In order to ensure that this study compared apples to apples, spent fuel storage sites were not included.

\subsection{Data}

This study investigated the demographic characteristics of populations living in either of the two study areas described above. The demographic variables included both racial/ethnic and socioeconomic variables. The racial/ethnic variables included the categories White, Black, Asian, Hispanic, Native American, Other, and Color. They are defined as: (1) Percent White is percent of all non-Hispanic Whites; (2) Percent Black is percent of non-Hispanic Blacks or African Americans; (3) Percent Asian is percent of Asian, and Native Hawaiian or Other Pacific Islander; (4) Percent Native American is percent of American Indian or Alaska Native; (5) Percent Other is percent of some other race who are not included in the White, Black, or African American, American Indian or Alaska Native, Asian, and Native Hawaiian or Other Pacific Islander race categories; and (6) Percent Color is percent of all other races except non-Hispanic Whites; and (7) Percent Hispanic is percent of people who are of Hispanic origin. The socioeconomic variables selected for inclusion were renter-occupied housing, unemployment rate, percent living in poverty, mean household income, and percent composition at the census-tract level.

In addition to the demographic variables here described, this study also included several other variables. To analyze any proximity-based disparities present in a given demographic variable, distance from a NPP was used, measured in Euclidean distance from the census-tract center point to the NPP in miles. The measurement was performed using ENVI's ArcMap program. This distance variable was used to examine whether and how disparities in certain demographic characteristics were associated with distance from a NPP.
To answer the research question, this study first secured access to multiple datasets. To investigate demography-based disparities in the study areas required three discrete datasets. First, for demographic characteristics, the author obtained data published by the U.S. Census Bureau and GeoLyticsnamely (1) U.S. Census 1990, long form, normalized to 2010 census-tract boundaries (GeoLytics 2012b); (2) U.S. Census 2000, long form, normalized to 2010 census-tract boundaries (GeoLytics 2012a); and (3) U.S. Census 2010/American Community Survey, 5-year estimate (GeoLytics 2012c). The use of census tract boundaries normalized to those of 2010 for data collected as part of the 1990 and 2000 censuses was vital to this study, as it allowed comparison of census data from the 1990, 2000, and 2010 surveys. Since the data are only available at the census-tract level, this study takes a census tract as the base geographical unit of analysis. The datasets that result from each respective survey include racial and ethnic subgroups-namely, White-alone, Hispanic-alone, American Indian- or Alaskan Native-alone, Asian-alone, Black or African American-alone, Native Hawaiian or Other Pacific Islander-alone, and Other-alone-as well as one additional category, "Two or more races," that is included only in the 2010 dataset. In addition, other socioeconomic data-such as gender, age, income, poverty, employment status, education, housing situation (owner-occupied versus renter-occupied), and citizenship status (native-born versus naturalized)—-were available from each survey.

Second, in order to regularize administrative boundaries for spatial analyses, the author downloaded the national-level shapefiles that join the geometry and certain select attributes from the 2010 Census TIGER/Line Shapefiles and the 2010 U.S. Census Summary File 1 Demographic Profile (DP1) for the United States and Puerto Rico from the United States Census Bureau's website (United States Census Bureau 2010).

Third, information including the location of each of the 104 nuclear reactors currently in operation in the United States was obtained from the NRC's website (U.S. NRC $2012 b)$. The data include general information on the reactors-namely, reactor type and containment type, design type, docket number, licensee, operating license issue date, commercial operation start date, renewed operation license issue date, and operating license expiration date. The author acquired latitude and longitude information for individual NPPs using Google Earth; the XY coordinates thus obtained were then manually entered into a separate sheet.

\section{Method}

The center point-distance approach was used to measure the exact distance between census-tract center point and the NPP. First, the author determined the geographic center point of each included census tract in ArcMap 10.1. Next, 
those geographic center points that fell within a 50-mile radius of the nearest NPP were identified using the "near" tool in ArcMap 10.1. This provided the exact distance between the census tracts' center points and the relevant NPP.

Descriptive statistics were computed for the sociodemographic characteristics of populations living within a 50-mile radius of one of the 65 NPPs currently in operation in the United States as well as for populations living in the outlying areas. The populations living within 50 miles of a NPP were then further subdivided into five categories, defined by distance: 0-10 miles from a NPP, 11-20 miles, 21-30 miles, 31-40 miles, and 41-50 miles; this was in addition to the broader category 0-50 miles. Using these six distance-based categories, this study examined the demography of the populations living at each distance and included nearby NPPs described as national, regional, urban, and individual. Statistical tests were conducted to investigate whether there were statistically significant differences in the demographic characteristics of populations living within a 50-mile radius as compared to those living in outlying areas. In doing so, this study utilized two independent-sample $T$ tests to identify any differences in the sociodemographic compositions of the two areas. The $T$ test analyses were conducted in STATA 12.

\section{Findings}

The discussion of the findings based on above mentioned research method is as follows.

\subsection{Overall Demographic Composition by Distance}

This section first presents the disparities that exist in certain sociodemographic characteristics, including racial, ethnic, and socioeconomic variables, between those communities within a 50-mile radius from a NPP (host communities) and those communities outside of a 50-mile radius, based on U.S. Census data for the years 1990, 2000, and 2010. It then describes the disparities in those same sociodemographic characteristics for communities that fall within one of the six distance categories - $0-10$ miles from the nearest NPP, 11-20 miles, 21-30 miles, 31-40 miles, 41-50 miles, 0-50 miles, and more than 50 miles from the nearest NPP, across the period spanning 1990-2010. Finally, the section discusses the overall sociodemographic characteristics of the populations living in NPP host communities and highlights the trends in these variables for the years 1990, 2000, and 2010.

As of 2010, a total of 96 million people lived within a 50-mile radius from the nearest NPP, whereas an estimated 208 million people lived in what are described as "outside areas" (Table 1), defined as areas that fall outside of a 50-mile radius from the nearest NPP. In other words, more than 3 persons out of every 10 (96 million out of 304 total U.S. population) lived within a 50-mile radius of a NPP according to the 2010 U.S. Census. Among the communities located within such a radius, $71.1 \%$ of the population classified themselves as White, $16 \%$ Black, $15 \%$ Hispanic, and $5 \%$ Asian, whereas among the communities located in outside areas, $75.1 \%$ of the population classified themselves as White, $10 \%$ Black, $16 \%$ Hispanic, and $5 \%$ Asian. In

Table 1 Demographic composition according to area, sorted by distance from any one of the 65 U.S.-based commercial NPPs, based on 2010 American Community Survey Data

\begin{tabular}{|c|c|c|c|c|c|c|c|}
\hline Distance (miles) & $0-10$ & $11-20$ & $21-30$ & $31-40$ & $41-50$ & $0-50$ & Outside\# \\
\hline Tracts & 908 & 3290 & 6204 & 7864 & 5129 & 23,395 & 49,662 \\
\hline Tract area (sq. miles) & 18,258 & 54,900 & 81,180 & 94,216 & 52,248 & 300,801 & 3495,942 \\
\hline Total population & $3,943,881$ & $13,749,623$ & $25,548,082$ & $32,349,698$ & $20,480,364$ & $96,071,648$ & $207,893,616$ \\
\hline White & $3,280,113$ & $10,988,148$ & $18,811,164$ & $22,006,806$ & $12,961,839$ & $68,048,072$ & $156,847,632$ \\
\hline Black & 408,088 & $1,593,169$ & 4078,036 & 5595,517 & 3807,400 & $15,482,210$ & $22,496,542$ \\
\hline Asian & 81,047 & 398,638 & 958,199 & 1849,310 & 1588,819 & 4876,013 & $9,801,153$ \\
\hline Native American & 11,233 & 41,975 & 77,305 & 125,688 & 76,503 & 332,704 & $2,147,761$ \\
\hline Others & 163,400 & 727,693 & 1623,379 & 2772,377 & 2045,804 & 7332,653 & $16,600,536$ \\
\hline Hispanic & 330,049 & 1440,563 & 3284,573 & 5287,229 & 3646,221 & $13,988,635$ & $33,738,896$ \\
\hline Color & 880,263 & $3,661,789$ & 8704,444 & $13,187,954$ & 9366,389 & $35,800,840$ & $71,591,664$ \\
\hline White $(\%)$ & 83.17 & 79.92 & 73.63 & 68.03 & 63.29 & 70.83 & 75.45 \\
\hline Black $(\%)$ & 10.35 & 11.59 & 15.96 & 17.30 & 18.59 & 16.12 & 10.82 \\
\hline Asian $(\%)$ & 2.06 & 2.90 & 3.75 & 5.72 & 7.76 & 5.08 & 4.71 \\
\hline Native American $(\%)$ & 0.28 & 0.31 & 0.30 & 0.39 & 0.37 & 0.35 & 1.03 \\
\hline Others $(\%)$ & 4.14 & 5.29 & 6.35 & 8.57 & 9.99 & 7.63 & 7.99 \\
\hline Hispanic $(\%)$ & 8.37 & 10.48 & 12.86 & 16.34 & 17.80 & 14.56 & 16.23 \\
\hline Color $(\%)$ & 22.32 & 26.63 & 34.07 & 40.77 & 45.73 & 37.26 & 34.44 \\
\hline Renter housing units (\%) & 22.17 & 25.66 & 28.78 & 33.05 & 34.54 & 30.69 & 28.73 \\
\hline
\end{tabular}


Table 1 continued

\begin{tabular}{llllllll}
\hline Distance (miles) & $0-10$ & $11-20$ & $21-30$ & $31-40$ & $41-50$ & $0-50$ & Outside\# \\
\hline College degree or higher (\%) & 28.11 & 30.22 & 29.97 & 30.27 & 29.98 & 30.03 & 26.90 \\
Unemployed (\%) & 7.21 & 7.35 & 7.99 & 8.47 & 8.29 & 8.09 \\
Poverty (\%) & 10.09 & 11.23 & 12.78 & 13.53 & 13.28 & 12.81 \\
Mean household income (\$) & 75,090 & 76,928 & 74,927 & 75,865 & 76,387 & 75,845 & 68,593 \\
\hline
\end{tabular}

Distance was measured between census-tract centroid points and NPP in miles. The category "Outside\#" includes all areas within the U.S. that do not fall within a 50-mile radius of any one of the 65 U.S.-based NPPs. Mean household income is real dollar value as of 2010

Data Source GeoLytics (2012c)

Table 2 Demographic composition according to area, sorted by distance from any one of the 65 U.S.-based commercial NPPs, based on 2000 American Community Survey Data normalized to 2010 U.S. Census boundaries

\begin{tabular}{|c|c|c|c|c|c|c|c|}
\hline Distance (miles) & $0-10$ & $11-20$ & $21-30$ & $31-40$ & $41-50$ & $0-50$ & Outside\# \\
\hline Tracts & 908 & 3290 & 6204 & 7864 & 5129 & 23,395 & 49,662 \\
\hline Tract area (sq. miles) & 18,258 & 54,900 & 81,180 & 94,216 & 52,248 & 300,801 & $3,495,942$ \\
\hline Total population & $3,462,639$ & $12,549,504$ & $24,021,128$ & $31,031,720$ & $19,531,042$ & $90,596,032$ & $190,825,872$ \\
\hline White & $2,967,500$ & $10,340,303$ & $18,184,338$ & $21,605,748$ & $12,720,314$ & $65,818,204$ & $145,535,520$ \\
\hline Black & 322,478 & 1363,193 & 3767,229 & 5317,959 & 3662,384 & $14,433,243$ & $19,928,496$ \\
\hline Asian & 46,067 & 257,474 & 628,868 & 1371,079 & 1145,248 & 3448,736 & $7,101,866$ \\
\hline Native American & 11,325 & 43,803 & 82,672 & 137,983 & 80,343 & 356,126 & $2,091,863$ \\
\hline Others & 115,385 & 544,534 & 1358,065 & 2598,859 & 1922,802 & 6539,645 & $16,168,205$ \\
\hline Hispanic & 182,469 & 926,000 & 2343,231 & 4081,065 & 2830,356 & $10,363,121$ & $24,875,360$ \\
\hline Color & 599,702 & 2738,645 & 7135,217 & $11,300,120$ & 8057,747 & $29,831,432$ & $57,076,336$ \\
\hline White (\%) & 85.70 & 82.40 & 75.70 & 69.62 & 65.13 & 72.65 & 76.27 \\
\hline Black (\%) & 9.31 & 10.86 & 15.68 & 17.14 & 18.75 & 15.93 & 10.44 \\
\hline Asian $(\%)$ & 1.33 & 2.05 & 2.62 & 4.42 & 5.86 & 3.81 & 3.72 \\
\hline Native American (\%) & 0.33 & 0.35 & 0.34 & 0.44 & 0.41 & 0.39 & 1.10 \\
\hline Others $(\%)$ & 3.33 & 4.34 & 5.65 & 8.37 & 9.84 & 7.22 & 8.47 \\
\hline Hispanic (\%) & 5.27 & 7.38 & 9.75 & 13.15 & 14.49 & 11.44 & 13.04 \\
\hline Color $(\%)$ & 17.32 & 21.82 & 29.70 & 36.41 & 41.26 & 32.93 & 29.91 \\
\hline Renter housing units (\%) & 23.22 & 26.62 & 30.41 & 35.18 & 36.99 & 32.61 & 29.92 \\
\hline College degree or higher (\%) & 23.93 & 26.36 & 26.02 & 26.28 & 25.66 & 26.00 & 23.63 \\
\hline Unemployed (\%) & 4.76 & 4.84 & 5.67 & 5.97 & 6.33 & 5.76 & 5.78 \\
\hline Poverty (\%) & 8.89 & 9.36 & 11.44 & 12.30 & 12.79 & 11.64 & 12.73 \\
\hline Mean household income (\$) & 73,790 & 76,448 & 74,420 & 75,114 & 75,252 & 75,095 & 68,422 \\
\hline
\end{tabular}

Distance was measured between census-tract centroid points and NPP in miles. The category "Outside\#" includes all areas within the U.S. that do not fall within a 50-mile radius of any one of the 65 U.S.-based NPPs. Mean household income is real dollar value as of 2010

Data Source GeoLytics (2012b)

addition, the category "Color" — a container category that includes the total population excluding non-Hispanic Whites-was more prevalent among communities within a 50 -mile radius of a NPP $(37 \%)$ than among communities in outside areas (34\%). In 2010, the overall U.S. population was $74.0 \%$ White, $13 \%$ Black, $16 \%$ Hispanic, and $5 \%$ Asian (and so, $34 \%$ Color). Communities within a 50-mile radius of a NPP include fewer non-Hispanic White people as compared to communities in outside areas, and therefore those communities near to a NPP include a greater percent of people of other races and ethnic groups-namely, Black,
Asian, and Hispanic - as compared to communities in outside areas. In comparison to those living in communities within a 50-mile radius of a NPP, the population of communities located in outside areas are poorer (they earn lower than the average household income); are less likely to live in renter-occupied housing units; are less likely to hold a college degree or higher; and are more likely to be employed. There are no notable differences in either age or gender between the two areas. I identified similar patterns for the sociodemographic characteristics of the communities for the years 2000 (Table 2) and 1990 (Table 3). 
Table 3 Demographic composition of according to area, sorted by distance from any one of the 65 U.S.-based commercial NPPs, based on 1990 American Community Survey Data normalized to 2010 U.S. Census boundaries

\begin{tabular}{|c|c|c|c|c|c|c|c|}
\hline Distance (miles) & $0-10$ & $11-20$ & $21-30$ & $31-40$ & $41-50$ & $0-50$ & Outside\# \\
\hline Tracts & 908 & 3290 & 6204 & 7864 & 5129 & 23,395 & 49,662 \\
\hline Tract area (sq. miles) & 18,258 & 54,900 & 81,180 & 94,216 & 52,248 & 300,801 & $3,495,942$ \\
\hline Total population & $3,000,656$ & $10,993,087$ & $21,902,998$ & $28,411,958$ & $17,765,938$ & $82,074,640$ & $166,634,720$ \\
\hline White & $2,660,292$ & $9,521,418$ & $17,634,048$ & $21,626,328$ & $12,821,285$ & $64,263,368$ & $135,563,232$ \\
\hline Black & 267,856 & 1129,307 & 3306,932 & 4743,254 & 3328,346 & $12,775,695$ & $17,154,732$ \\
\hline Asian & 29,007 & 155,171 & 392,028 & 854,679 & 712,228 & 2143,113 & $5,083,769$ \\
\hline Native American & 10,030 & 33,101 & 63,304 & 110,277 & 61,509 & 278,221 & $1,736,823$ \\
\hline Others & 33,557 & 153,874 & 506,758 & 1077,356 & 842,613 & 2614,158 & $7,095,939$ \\
\hline Hispanic & 100,076 & 462,167 & 1528,885 & 2593,858 & 1816,292 & 6501,278 & $15,398,823$ \\
\hline Color & 402,059 & 1766,880 & 5228,348 & 8116,981 & 5787,093 & $21,301,360$ & $38,983,632$ \\
\hline White (\%) & 88.66 & 86.61 & 80.51 & 76.12 & 72.17 & 78.30 & 81.35 \\
\hline Black $(\%)$ & 8.93 & 10.27 & 15.10 & 16.69 & 18.73 & 15.57 & 10.29 \\
\hline Asian (\%) & 0.97 & 1.41 & 1.79 & 3.01 & 4.01 & 2.61 & 3.05 \\
\hline Native American (\%) & 0.33 & 0.30 & 0.29 & 0.39 & 0.35 & 0.34 & 1.04 \\
\hline Others $(\%)$ & 1.12 & 1.40 & 2.31 & 3.79 & 4.74 & 3.19 & 4.26 \\
\hline Hispanic (\%) & 3.34 & 4.20 & 6.98 & 9.13 & 10.22 & 7.92 & 9.24 \\
\hline Color $(\%)$ & 13.40 & 16.07 & 23.87 & 28.57 & 32.57 & 25.95 & 23.39 \\
\hline Renter housing units (\%) & 25.11 & 28.02 & 31.89 & 36.70 & 38.20 & 34.12 & 31.26 \\
\hline College degree or higher $(\%)$ & 18.73 & 21.62 & 21.43 & 22.14 & 21.36 & 21.59 & 19.71 \\
\hline Unemployed (\%) & 5.52 & 5.20 & 6.14 & 6.53 & 6.46 & 6.19 & 6.37 \\
\hline Poverty (\%) & 9.57 & 9.59 & 11.84 & 12.43 & 11.90 & 11.67 & 13.83 \\
\hline Mean household income $(\$)$ & 65,336 & 68,761 & 67,584 & 68,689 & 69,938 & 68,549 & 60,443 \\
\hline
\end{tabular}

Distance was measured between census-tract centroid points and NPP in miles. The category "Outside\#" includes all areas within the U.S. that do not fall within a 50-mile radius of any one of the 65 U.S.-based NPPs. Mean household income is real dollar value as of 2010

Data Source GeoLytics (2012a)
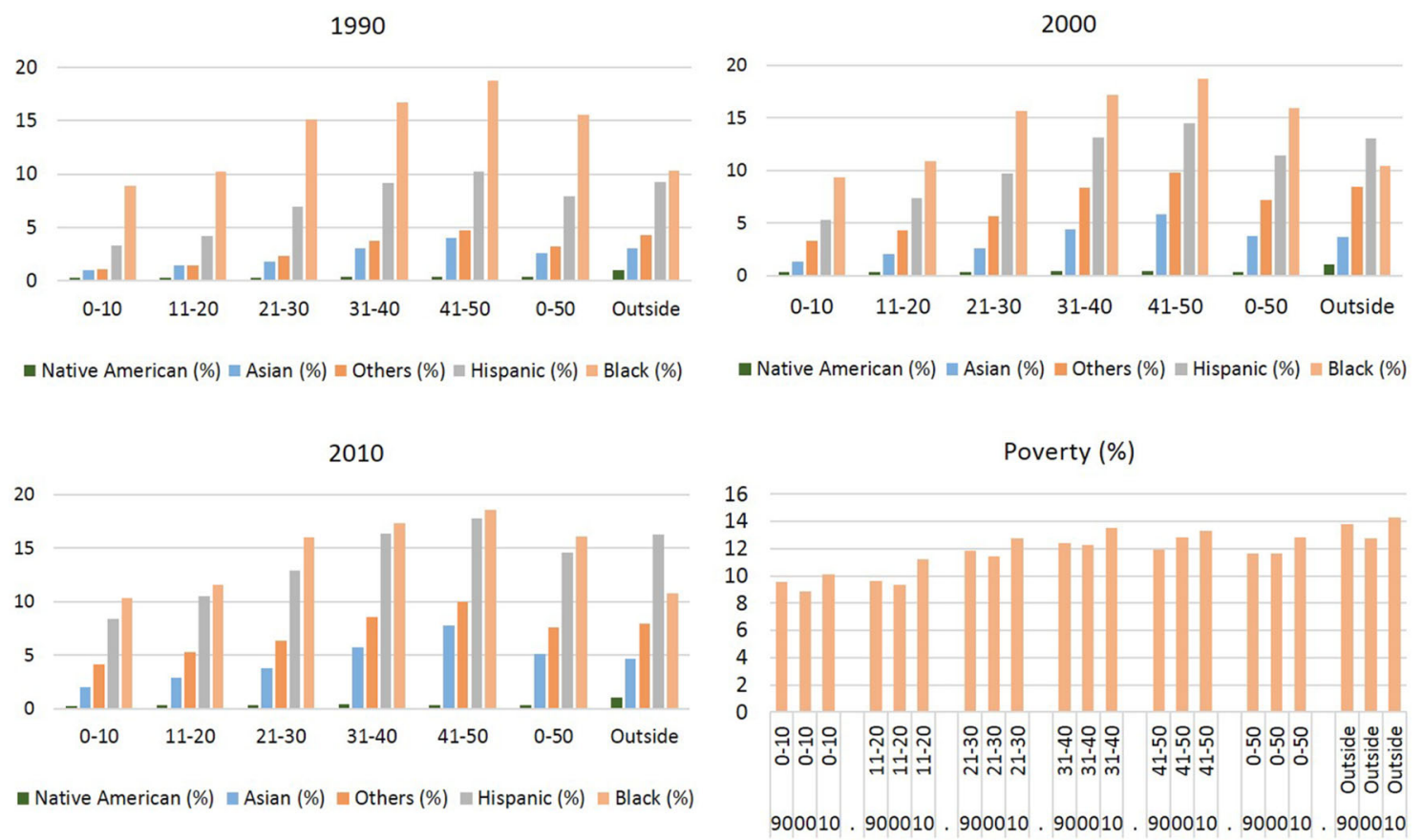

Fig. 2 Demographic trends (race/ethnicity) in the areas surrounding any one of the 65 U.S.-based commercial NPPs, as sorted by distance 
100
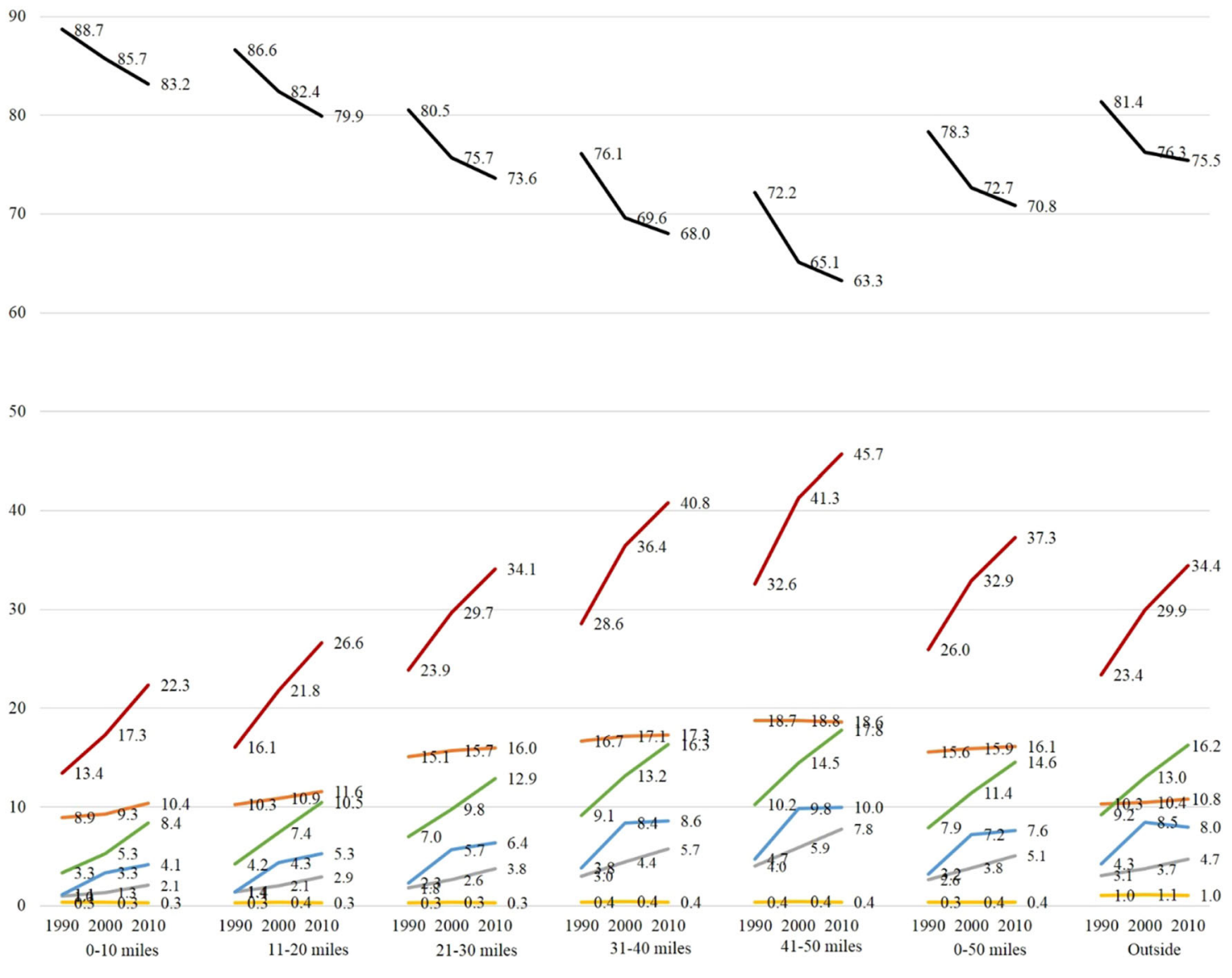

—White (\%) — Black (\%) — Asian (\%) — Native American (\%) — Others (\%) — Hispanic (\%) —Color (\%)

Fig. 3 Demographic trends (race/ethnicity) in the areas surrounding any one of the 65 U.S.-based commercial NPPs, as sorted by distance

This study also found that percent White was negatively associated with distance within $0-50$ miles from a $\mathrm{NPP}$ - that is, in the nearby area the greater the distance from a NPP, the lower the percentage of White people living in the communities. For the 2010 data, percent White was observed as $83.17,79.92,73.63,68.03$, and $63.29 \%$, in the 0-10 miles, 11-20 miles, $21-30$ miles, 31-40 miles, and 41-50 miles categories, respectively (Table 1). The percentages for other racial and ethnic groups-namely Black, Asian, Hispanic, and Native American-meanwhile, were positively associated with distance within 0-50 miles from a NPP; that is, the greater the distance from a NPP, the higher the percent of non-White peoples and households in the communities. Similarly, the percent of people living in poverty, the unemployment rate, the percent of people holding a college-degree, and the mean household income were all positively associated with distance from a NPP. In contrast, the percent of native-born citizens was negatively associated with distance. Similar demographic patterns were observed in the U.S. Census data for the years 2000 (Table 2) and 1990 (Table 3), as well.

Interesting demographic trends emerged when examining the data over the past two decades (Figs. 2 and 3). First, there was a notable trend of decreasing percent White at every distance, with a corresponding increase in percent nonWhite over that same period (Fig. 2). A minimal increase is seen in both percent Black and percent Asian in each of the 3 years. From 1990 to 2000, the percent of people living in poverty and the percent unemployed showed a slight increase, while those same figures show a sharp increase from 2000 to 2010 (Fig. 3).

\subsection{Overall Differences in the Demographic Characteristics}

This section presents findings pertaining to the overall demographic characteristics of the populations analyzed, 
sorted into two groups - those within a 50-mile radius of a NPP and those in the outside areas (Table 4). The analyses include 49,215 census tracts in the outside areas across the United States, and an additional 23,163 census tracts drawn from those areas within a 50-mile radius of a NPP. Unequal variance Welch $t$ test was used for the analyses. The result shows that, as compared to the outside areas, the populations living within a 50-mile radius included a higher percent Black (6.86 \%), percent Asian (0.39\%), and percent Color (4.37\%) as of 2010. The difference was statistically significant at the $p<0.001$ level. In contrast, in the outlying areas the populations included higher percent White, percent Native American, percent Other, and percent Hispanic. Again, the difference was statistically significant at the $p<0.001$ level. A similar pattern can be observed in data for the years 2000 and 1990, with the lone exception that percent Asian was higher in the outlying areas in those years. From 1990 to 2010 , the disparity in percent Black, percent Asian, and percent
Color between the two areas has continued to widen. In other words, there is an increasing trend to see a greater percent Black, percent Asian, and percent Color among the populations living within a 50-mile radius of a NPP.

\section{Discussion and Conclusion}

First, $8 \%(300,801$ square miles) of the total land area of the United States (3.80 million square miles) is occupied by host communities located within a 50-mile radius of a NPP. This means that the area that could be affected by NPPs and any accidents that might occur at them is objectively large. Even the definition of a 50-mile radius as the extent of the area that would be impacted remains open to debate given the new data still being generated and analyzed in the aftermath of the most recent core meltdown-type accident, at Fukushima NPP.

Table 4 Results of two independent-sample $T$ tests (Welch's $T$ test) calculated to identify differences in the demographic composition of populations living within a 50-mile radius of and populations living in the outlying areas surrounding a U.S.-based NPP as of 2010

\begin{tabular}{|c|c|c|c|c|c|c|c|c|c|}
\hline & & Count & SE & N1 & Mean 1 & $\mathrm{~N} 2$ & Mean 2 & Diff. & $t$ \\
\hline \multirow[t]{7}{*}{2010} & White & 72,378 & 0.20 & 49,215 & 75.42 & 23,163 & 69.32 & $6.101 * * *$ & $(29.89)$ \\
\hline & Black & 72,378 & 0.18 & 49,215 & 11.42 & 23,163 & 18.28 & $-6.857 * * *$ & $(-38.52)$ \\
\hline & Asian & 72,378 & 0.07 & 49,215 & 4.38 & 23,163 & 4.77 & $-0.391 * * *$ & $(-5.56)$ \\
\hline & Native American & 72,378 & 0.04 & 49,215 & 1.14 & 23,163 & 0.36 & $0.782 * * *$ & $(21.09)$ \\
\hline & Others & 72,378 & 0.08 & 49,215 & 7.63 & 23,163 & 7.27 & $0.365 * * *$ & $(4.57)$ \\
\hline & Hispanic & 72,378 & 0.17 & 49,215 & 15.21 & 23,163 & 13.55 & $1.655 * * *$ & $(9.97)$ \\
\hline & Color & 72,378 & 0.24 & 49,215 & 33.78 & 23,163 & 38.15 & $-4.372 * * *$ & $(-18.13)$ \\
\hline \multirow[t]{7}{*}{2000} & White & 72,865 & 0.21 & 49,551 & 76.59 & 23,314 & 71.85 & $4.742 * * *$ & $(23.03)$ \\
\hline & Black & 72,865 & 0.18 & 49,551 & 10.67 & 23,314 & 17.30 & $-6.628 * * *$ & $(-37.52)$ \\
\hline & Asian & 72,865 & 0.06 & 49,551 & 3.54 & 23,314 & 3.61 & -0.078 & $(-1.30)$ \\
\hline & Native American & 72,865 & 0.04 & 49,551 & 1.19 & 23,314 & 0.42 & $0.774 * * *$ & $(20.84)$ \\
\hline & Others & 72,865 & 0.09 & 49,551 & 8.05 & 23,314 & 6.93 & $1.129 * * *$ & $(12.94)$ \\
\hline & Hispanic & 72,865 & 0.15 & 49,551 & 12.29 & 23,314 & 10.65 & $1.642 * * *$ & $(10.80)$ \\
\hline & Color & 72,865 & 0.24 & 49,551 & 29.26 & 23,314 & 33.28 & $-4.022 * * *$ & $(-17.06)$ \\
\hline \multirow[t]{7}{*}{1990} & White & 72,704 & 0.20 & 49,403 & 82.23 & 23,301 & 78.47 & $3.764 * * *$ & (19.06) \\
\hline & Black & 72,704 & 0.17 & 49,403 & 9.75 & 23,301 & 15.68 & $-5.928 * * *$ & $(-33.88)$ \\
\hline & Asian & 72,704 & 0.05 & 49,403 & 2.84 & 23,301 & 2.47 & $0.376^{* * *}$ & $(6.91)$ \\
\hline & Native American & 72,704 & 0.04 & 49,403 & 1.15 & 23,301 & 0.37 & $0.777 * * *$ & $(20.72)$ \\
\hline & Others & 72,704 & 0.07 & 49,403 & 4.04 & 23,301 & 3.05 & $0.984 * * *$ & $(14.14)$ \\
\hline & Hispanic & 72,704 & 0.13 & 49,403 & 8.93 & 23,301 & 7.55 & $1.381 * * *$ & $(10.50)$ \\
\hline & Color & 72,704 & 0.22 & 49,403 & 22.44 & 23,301 & 25.58 & $-3.145^{* * *}$ & $(-14.18)$ \\
\hline
\end{tabular}

Mean $1=$ the mean percent demographic characteristics in outlying area across the United States

Mean 2 = the mean percent demographic characteristics in areas within a 50-mile radius of a NPP

Difference obtained by subtracting Mean 2 from Mean 1; (Mean 1 - Mean 2)

$\mathrm{t}$ statistics in parentheses

$* p<0.05$

$* * p<0.01$

$* * * p<0.001$ 
In addition to this large potentially impacted area, the findings also reveal that 96 million people out of a total population of 304 million live in host communities. This segment of the population is significantly larger than the estimated 22 million people who lived within three miles of a toxic release inventory (TRI) facility in the United States. (Bullard et al. 2007). The largest group of host communities-those within a 50-mile radius of Indian Point Nuclear Power Plant in New York-is home to approximately 15 million out of the 96 million people who live in such proximity to a U.S.-based NPP. The host communities include among their populations a lower percent White and a higher percent Black, Asian, and Color than compared to other communities.

The disparities in the demographic characteristics that exist between host and non-host communities are statistically significant. This large population size and the disparities in that population's demographic characteristics imply that particular racial minority groups are disproportionately shouldering the environmental hazards and risks that come attached to nuclear power. In addition, the large population living in host communities presents challenges in terms of disaster management, including in devising efficient and effective rescue and mitigation plans. The NRC emergency planning and preparation process appears not to take into account the sheer size of the potentially impacted population in its existing emergency evacuation, sheltering, and other action plans (U.S. NRC 2011a).

There is no detailed evacuation plan available for the host communities, especially in the most densely populated areas surrounding the Indian Point NPP. It is not an easy or simple task to evacuate or shelter some 15 million people. When people are gripped by panic, traffic congestion is inevitable. According to the notion of environmental justice as defined by the EPA, from a protection perceptive, environmental justice is achieved when everyone enjoys the same degree of protection from environmental and health hazards. Based on this study's statistical analyses, the bottom line conclusion is that there is no equal protection from the potential risks associated with commercial NPPs. The findings in this study provide a wake-up call for all concerned authorities to look carefully into issues associated with the increasing population involuntarily exposed to nuclear power plant-induced disasters for the past two decades.

Open Access This article is distributed under the terms of the Creative Commons Attribution 4.0 International License (http://crea tivecommons.org/licenses/by/4.0/), which permits unrestricted use, distribution, and reproduction in any medium, provided you give appropriate credit to the original author(s) and the source, provide a link to the Creative Commons license, and indicate if changes were made.

\section{References}

Acton, J.M., and M. Hibbs. 2012. Why Fukushima was preventable. Washington DC: Carnegie Endowment for International Peace. http://carnegieendowment.org/2012/03/06/why-fukushima-waspreventable/a0i7. Accessed 6 Mar 2013.

Anzai, K., N. Ban, T. Ozawa, and S. Tokonami. 2012. Fukushima Daiichi Nuclear Power Plant accident: Facts, environmental contamination, possible biological effects, and countermeasures. Journal of Clinical Biochemistry and Nutrition 50(1): 2-8.

Astakhova, L.N., L.R. Anspaugh, G.W. Beebe, A. Bouville, V.V. Drozdovitch, V. Garber, et al. 1998. Chernobyl-related thyroid cancer in children of Belarus: A case-control study. Radiation Research 150(3): 349-356.

Baba, M. 2013. Fukushima accident: What happened? Radiation Measurements 55: 17-21.

Blevins, M.R., and R.L. Andersen. 2011. Radiation protection at U.S. nuclear power plants-Today and tomorrow. Health Physics 100(1): 35-38.

Bolin, B., A. Nelson, E.J. Hackett, K.D. Pijawka, C.S. Smith, D. Sicotte, et al. 2002. The ecology of technological risk in a Sunbelt city. Environment and Planning A 34(2): 317-339.

Bowen, W.M., M.J. Salling, K.E. Haynes, and E.J. Cyran. 1995. Toward environmental justice: Spatial equity in Ohio and Cleveland. Annals of the Association of American Geographers 85(4): 641-663.

Bullard, R.D. 1996. Environmental justice: It's more than waste facility siting. Social Science Quarterly 77(3): 493-499.

Bullard, R.D., P. Mohai, R. Saha, and B. Wright. 2007. Toxic wastes and race at twenty 1987-2007: A report prepared for the United Church of Christ Justice \& Witness Ministries. Cleveland, $\mathrm{OH}$ : United Church of Christ Justice \& Witness Ministries. http:// d3n8a8pro7vhmx.cloudfront.net/unitedchurchofchrist/legacy_url/ 491/toxic-wastes-and-race-at-twenty-1987-2007.pdf?1418423933. Accessed 9 Aug 2013.

Canu, I.G., E.D. Ellis, and M. Tirmarche. 2008. Cancer risk in nuclear workers occupationally exposed to uranium-Emphasis on internal exposure. Health Physics 94(1): 1-17.

Cappiello, D., and J. Donn. 2011. Earthquake risk to U.S. nuclear reactors is greater than previously thought. New York: The Associated Press. http://blog.nola.com/business_impact/print. html?entry=/2011/09/earthquake_risk_to_us_nuclear.html. Accessed 12 Aug 2013.

Cardis, E., A. Kesminiene, V. Ivanov, I. Malakhova, Y. Shibata, V. Khrouch, et al. 2005. Risk of thyroid cancer after exposure to I-131 in childhood. Journal of the National Cancer Institute 97(10): 724-732.

Cutter, S.L., D. Holm, and L. Clark. 1996. The role of geographic scale in monitoring environmental justice. Risk Analysis 16(4): 517-526.

Cyranoski, D., and G. Brumfiel. 2011. Fukushima impact is still hazy. Nature 477(7363): 139-140.

GeoLytics. 2012a. 2000 long form in 2010 boundaries. http://www. geolytics.com/USCensus,2000-Long-Form-in-2010-Boundaries, Products.asp. Accessed 9 Oct 2013.

GeoLytics. 2012b. Census 1990 in 2010 boundaries. http://www. geolytics.com/USCensus. Accessed 9 Oct 2013.

GeoLytics. 2012c. Census 2010/American community survey (ACS). http://www.geolytics.com/USCensus, Census2010ACS,Categories. asp. Accessed 9 Oct 2013.

Giugni, M. 2004. Social protest and policy change: Ecology, antinuclear, and peace movements in comparative perspective. Lanham, MD: Rowman \& Littlefield.

Golay, M.W., I.I. Saragossi, and M. Wilefert. 1977. Comparative analysis of United States and French nuclear power plant siting 
and construction regulatory policies and their economic consequences. Working Paper (MIT-EL 77-044-WP). Cambridge, MA, Energy Laboratory and Department of Nuclear Engineering, Massachusetts Institute of Technology MIT: The Joint Nuclear Engineering Department/Energy Laboratory Light Water Reactor Project, the US Energy Research and Development Administration.

Gottlieb, R. 2005. Forcing the spring: The transformation of the American environmental movement (Rev. and updated edn.). Washington, DC: Island Press.

Greenberg, M.R., and D.A. Krueckeberg. 1974. Demographic analysis for nuclear power plant siting: A set of computerized models and a suggestion for improving siting practices. Computers \& Operations Research 1(34): 497-506.

Hochfelder, D. 1999. The promise of nuclear power. Proceedings of the IEEE 87(8): 1405-1408.

Kan, N. 2013. Panel discussion. The Fukushima nuclear accident: Ongoing lessons for New York. Symposiums on Fukushima and Nuclear Power. New York. Accessed 8 Oct 2013.

Koch, W. 2011. Earthquake readiness of U.S. nuclear power plants is unclear. USA Today. http://usatoday30.usatoday.com/tech/ science/environment/story/2011-08-25/Earthquake-readiness-ofUS-nuclear-power-plants-is-unclear/50141704/1. Accessed 12 Oct 2013.

Lazare, S. 2013. Radition soars 6,700 times leagl limit as Fukushima diasters continue unabated. CommonDreams.org. http://www. commondreams.org. Accessed 25 Oct 2013.

Margai, F.M. 2010. Environmental health hazards and social justice: Geographical perspectives on race and class disparities. London: Earthscan.
Mariottee, M. 2006. The NRC's reactor licensing process: An overview. Nuclear Information and Resource Services (NIRS).

Thakur, P., S. Ballard, and R. Nelson. 2013. An overview of Fukushima radionuclides measured in the northern hemisphere. Science of the Total Environment 458-460: 577-613.

United States Census Bureau. 2010. TIGER/Line ${ }^{\circledR}$ shapefiles prejoined with demographic data: 2010 census summary file 1 demographic profile (DP1). http://www.census.gov/geo/mapsdata/data/tiger-data.html. Accessed 25 Nov 2013.

U.S. NRC (United States Nuclear Regulatory Commission). 2011a. Emergency preparedness at nuclear power plants. U.S. Nuclear Regulatory Commission.

U.S. NRC (United States Nuclear Regulatory Commission). 2011b. Nuclear Regulartory Commission. http://www.nrc.gov. Accessed 12 Aug 2012.

U.S. NRC (United States Nuclear Regulatory Commission). 2012a. 2012-2013 information digest (NUREG-1350, vol. 24). US Nuclear Regulatory Commission. http://www.nrc.gov/reading$\mathrm{rm} /$ doc-collections/nuregs/staff/sr1350/v24/sr1350v24.pdf. Accessed 12 Aug 2012.

U.S. NRC (United States Nuclear Regulatory Commission). 2012b. Information digest, 2011-2012. http://www.nrc.gov/reading-rm/ doc-collections/nuregs/staff/sr1350/. Accessed 12 Aug 2012.

U.S. NRC (United States Nuclear Regulatory Commission). 2012c. Nuclear power plant licensing process. http://www.nrc.gov. Accessed 12 Aug 2012.

Yamaguchi, M. 2013. Fukushima leak: Cause revealed to be overflowing tank. The Huffington Post. http://www.huffingtonpost.com. Accessed 12 Aug 2012. 